\title{
Sekolah TK dan PAUD Peduli Kesehatan Gigi
}

\section{Laelia Dwi Anggraini'), Pipiet Okti K²), Likky Tiara Alphianti3)}

1,2,3) Program Studi Pendidikan Dokter Gigi, Fakultas Kedokteran dan Ilmu Kesehatan Universitas Muhammadiyah Yogyakarta Email: laelia_dentist@yahoo.com; laelia.dwi@umy.ac.id

10.18196/ppm.32.177

\begin{abstract}
Abstrak
Menurut WHO, lebih dari 50 juta jam sekolah per tahun hilang sebagai akibat yang ditimbulkan oleh sakit gigi pada anak. Surkesnas melaporkan 62,4\% penduduk merasa terganggu pekerjaan/sekolah karena sakit gigi (rata-rata per tahun 3,86\%). Anggraini melaporkan anak free karies pada salah satu SD favorit di Yogyakarta adalah 10\%. Konsep program ini bertujuan untuk memberi materi kesehatan gigi pada guru TK dan PAUD serta mengajak mereka peduli akan kesehatan gigi murid-muridnya. Metode yang digunakan adalah pemberian materi dengan penyuluhan dan setelahnya mengisi kuesioner. Kuesioner meliputi pengertian kesehatan gigi, asal mereka mendapatkan informasi kesehatan gigi, pengetahuan menggosok gigi, konsep gosok gigi, dan konsep pertolongan pertama saat murid sakit gigi. Implikasi program ini adalah masyarakat sekolah TK/PAUD diajak berpikir, bersikap, dan bertindak untuk membangun dan mengembangkan diri melalui kepedulian terhadap kesehatan gigi Data kuesioner menunjukkan 100\% guru TK/PAUD setuju bahwa pengetahuan kesehatan gigi adalah hal penting. Menggosok gigi penting untuk anak TK/PAUD (97,7\%). Menggosok gigi sebaiknya dilakukan tiga kali sehari (84,10\%). Guru tahu cara menggosok gigi yang baik dan benar (84,10\%). Besaran jumlah pasta gigi yang diletakkan pada sikat gigi anak adalah sebesar biji kacang polong (54,50\%). Waktu menyikat gigi anak 1-2 menit (65,9\%). Sebanyak 50,00\% menyatakan anak perlu minum obat jika sakit gigi. Jika anak bengkak giginya, anak segera minum obat, kumur garam, dan periksa ke dokter gigi (68,20\%). Kesimpulannya adalah pengetahuan tentang kesehatan gigi perlu ditingkatkan pada kalangan pendidik guru TK dan PAUD (belum 100\% jawaban benar dari data kuesioner) dan perlu ada kesadaran pentingnya kepedulian sekolah dalam masalah kesehatan gigi dan mulut (97,60\% - 100\% responden setuju terkait pelatihan virtual dan penambahan pengetahuan tentang kesehatan gigi anak).
\end{abstract}

Kata kunci : TK/PAUD, peduli, kesehatan gigi

Pendahuluan

Menurut WHO, lebih dari 50 juta jam sekolah per tahun hilang sebagai akibat yang ditimbulkan oleh sakit gigi pada anak. Surkesnas melaporkan $62,4 \%$ penduduk merasa terganggu pekerjaan/sekolah karena sakit gigi (rata-rata pertahun 3,86\%) ${ }^{1)}$. Karies merupakan suatu penyakit jaringan keras gigi, yaitu email, dentin, dan sementum, yang disebabkan oleh aktivitas suatu jasad renik dalam suatu karbohidrat yang dapat diragikan. ${ }^{2)}$ Karies gigi adalah penyakit jaringan gigi yang ditandai dengan kerusakan jaringan, dimulai dari permukaan gigi (ceruk, fisura, dan daerah interproksimal) meluas ke arah pulpa. Karies gigi terdapat di seluruh dunia, tanpa memandang umur, bangsa ataupun keadaan ekonomi. Menurut penelitian di negara-negara Eropa, Amerika, dan Asia, termasuk Indonesia, ternyata 80 -95\% anak di bawah usia 18 tahun terserang karies gigi ${ }^{3)}$. Riskesdas menyatakan prevalensi nasional masalah kesehatan gigi dan mulut 23,5\%. Prevalensi menggosok gigi tiap hari pada penduduk umur 10 tahun $\mathrm{k}$ eatas $91,1 \%$ (mandi pagi \& sore). Proporsi gosok gigi sesudah sarapan pagi 12,6\%, dan sebelum tidur malam 28,7\%. Prevalensi nasional karies aktif 43,9\%. Prevalensi pengalaman karies $72,1 \%$. Prevalensi nasional masalah kesehatan gigi dan mulut umur 5-9 th 21,6\% dan 1014 th $20,6 \%$. Prevalensi gosok gigi tiap hari pada penduduk umur $10-14$ tahun $93,8 \%(90,7$ mandi pagi \& sore). Proporsi gosok gigi sesudah sarapan pagi 11,8\% dan sebelum tidur malam 25\%. Prevalensi nasional karies aktif umur 12 tahun 29,8\%. Prevalensi pengalaman karies umur 12 tahun 36,1 \% DMT-T $=0,91{ }^{4)}$ Prevalensi free caries di SD Muh Sapen adalah 10\% 5). Performed Treatment Indeks (PTI) anak usia 12 tahun 0,7 \%. Requitment Treatmen Indeks (RTI) anak usia 12 tahun $62,3 \%$ dan 37,52 \% murid SD telah diperiksa, 22,1\% memerlukan 
perawatan dan $10,43 \%$ mendapat perawatan ${ }^{4)}$. Hal inilah yang melatarbelakangi kegiatan ini perlu dilakukan.

Risiko karies adalah kemungkinan berkembangnya karies pada individu atau terjadinya perubahan status kesehatan yang mendukung terjadinya karies pada suatu periode tertentu. Risiko karies bervariasi pada setiap individu. Hal ini tergantung pada keseimbangan faktor pencetus dan penghambat terjadinya karies. Menurut American Academy of Pediatric Dentistry, penilaian risiko karies pada anak dilihat berdasarkan atas tiga bagian besar indikator karies, yaitu: kondisi klinik, karakteristik lingkungan, dan kondisi kesehatan umum ${ }^{6)}$. Untuk menentukan seseorang memiliki risiko karies yang tinggi atau rendah, perlu dilakukan serangkaian pemeriksaan atau evaluasi guna mengidentifikasi faktor risiko yang berperan dalam meningkatkan risiko terjadinya karies gigi ${ }^{7}$. Anak yang berisiko karies tinggi harus mendapat perhatian khusus karena perawatan intensif dan ekstra harus segera dilakukan untuk menghilangkan karies atau setidaknya mengurangi risiko karies, dari tinggi menjadi rendah pada tingkatan karies yang dapat diterima di kelompok umur tertentu. Ini dilakukan agar target pencapaian gigi sehat tahun 2010 menurut WHO dapat tercapai ${ }^{6)}$.

Analisis situasi saat ini di wilayah DKI Jakarta pada hasil evaluasi karies gigi anak balita tahun 1993 menemukan 44,4\% anak mengalami susah makan karena keluhan sakit gigi. Hal ini berdampak sebanyak 13,1\% anak mempunyai status gizi di bawah normal. ${ }^{8)}$ Di SD Kalimantan Barat, ditemukan kegiatan menyikat gigi massal dengan memakai pasta gigi berfluor setiap hari. Cara ini terbukti dapat menurunkan prevalensi penyakit karies secara bermakna, yakni $40 \%$ selama 3 tahun. Program Tooth Brushing Campaign ini merupakan program utama dalam menurunkan penyakit karies di negara Jepang, Malaysia, Thailand, dan Filipina. Kegiatan ini tidak memerlukan teknologi canggih. Kegiatan ini dilaksanakan di bawah bimbingan dokter gigi dan berkoordinasi dengan guru atau dokter kecil. ${ }^{9)}$ Pendidikan kesehatan saja tidak cukup. Pendidikan kesehatan akan meningkatkan pengetahuan, tetapi tidak akan mengakibatkan perubahan perilaku. Perubahan perilaku membutuhkan lingkungan yang mendukung dan keterampilan. Mengingat beberapa hal di atas, perlunya pelaksanaan bakti sosial di masyarakat 10)

Tujuan konsep Taman Kanak-Kanak (TK) dan PAUD peduli kesehatan gigi adalah mengedukasi masyarakat sekolah dengan titik berat pada personal, institusi, dan community. Personal artinya kegiatan ini dilakukan dengan melibatkan guru dan karyawan sekolah, misalnya pelayanan edukasi yang bersifat seorang demi seorang. Institusi artinya melibatkan organisasi kelembagaan tertentu dan jejaringnya, dalam hal ini adalah sekolah TK dan PAUD terkait. Masyarakat artinya masyarakat sekolah, yakni guru, karyawan, komite sekolah, dan orang tua peserta didik. Masyarakat adalah suatu hal penting dalam sebuah community. Sasaran sekolah TK dan PAUD peduli kesehatan gigi ialah mengajak masyarakat sekolah berpikir, bersikap dan bertindak untuk membangun dan mengembangkan diri agar peduli dengan kesehatan gigi dan rongga mulutnya. Sebuah institusi secara langsung mengembangkan dan menerapkan teori pembangunan masyarakat melalui keterlibatan dosen sebagai bagian dari caturdharma perguruan tinggi. ${ }^{10)}$

Metode Pelaksanaan

Adapun langkah-langkah pelaksanaan kegiatan sebagai berikut. 
1. Mengadakan workshop (WS) persiapan, meliputi WS pertama tentang brainstorming yakni konsep TK Peduli Kesehatan Gigi. WS kedua tentang kriteria TK Peduli Kesehatan Gigi dan WS ketiga tentang persiapan seminar serta pembuatan bahan ajar untuk TK.

2. Berikutnya pemilihan khalayak/responden, yakni TK/PAUD yang telah menjadi MoU dari RSGM UMY.

3. Berikutnya adalah keterlibatan peran ibu. Wanita adalah hal penting dalam suatu penggerakan masyarakat, termasuk masyarakat sekolah.

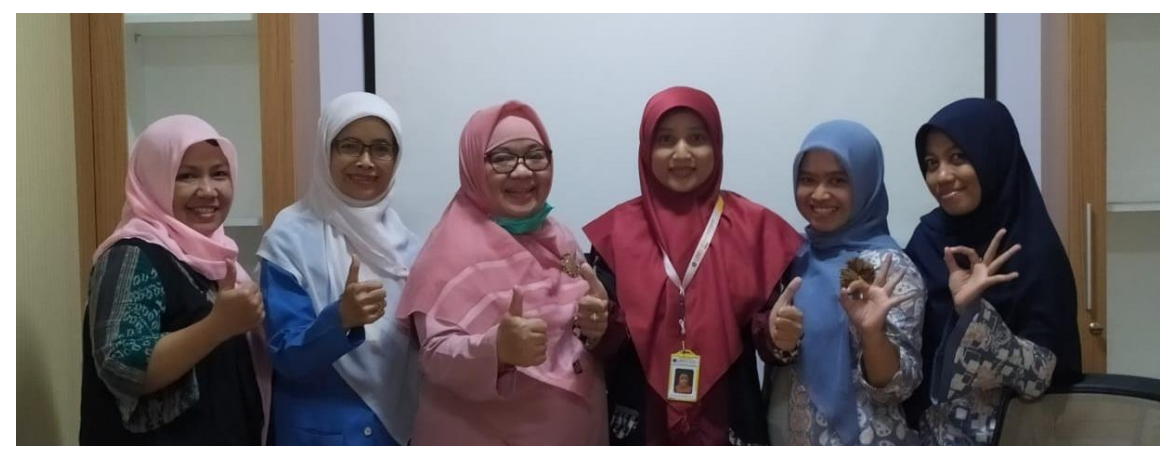

Gb 1. Workshop Sekolah Peduli Kesehatan Gig

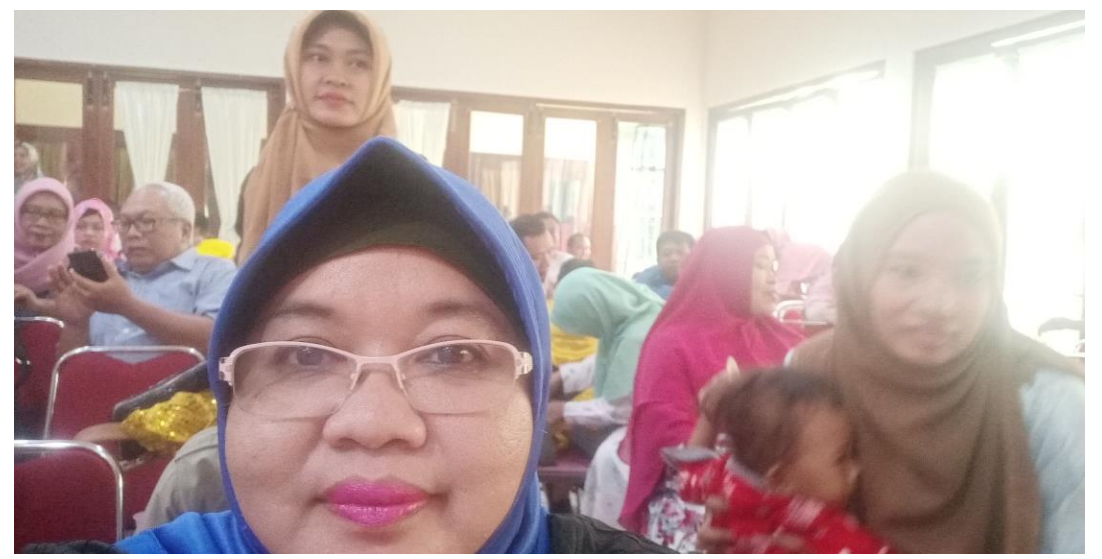

Gb 2. Pelibatan para tokoh masyarakat sekolah

Bahan dan alat yang digunakan dalam pengabdian ini adalah materi penyuluhan kesehatan gigi, berupa power point presentation, laptop, viewer, alat diagnosis set lengkap (untuk latihan pemeriksaan gigi), model gigi akrilik, kertas dan alat tulis.

Materi diberikan kepada responden yang merupakan perwakilan TK/PAUD, kemudian dilakukan pengumpulan data melalui kuesioner. Analisis data sederhana berupa persentase dilakukan untuk menilai hasil akhir kegiatan. 


\section{Hasil dan Pembahasan}

Apakah Bpk/lbu/Sdr berkenan mengisi kuesioner ini

44 tanggapan

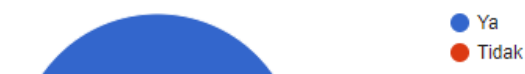

$100 \%$

Gambar 3. Kesediaan mengisi kuesioner

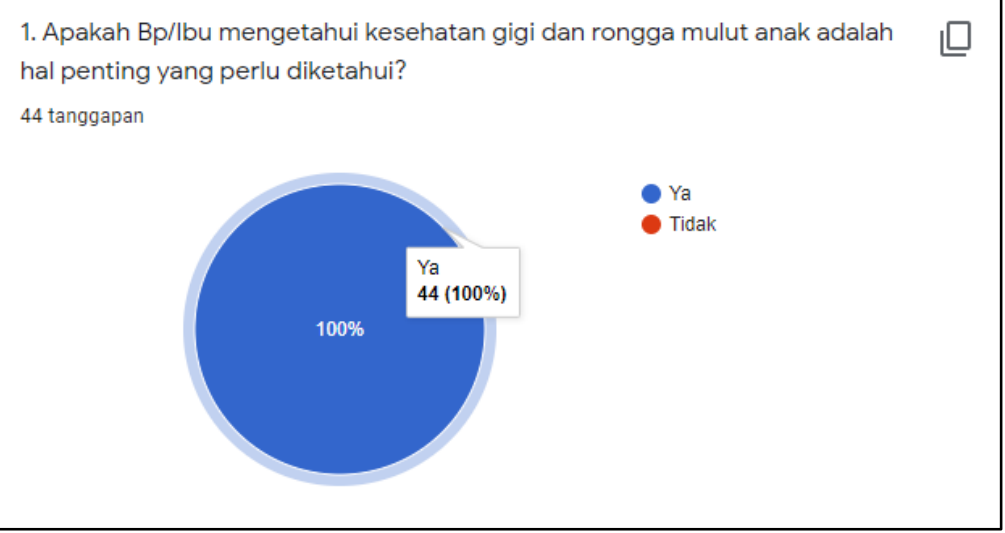

Gambar 4. Pengetahuan kesehatan gigi dan mulut 
3. Apakah menggosok gigi penting untuk anak TK/PAUD?

43 tanggapan

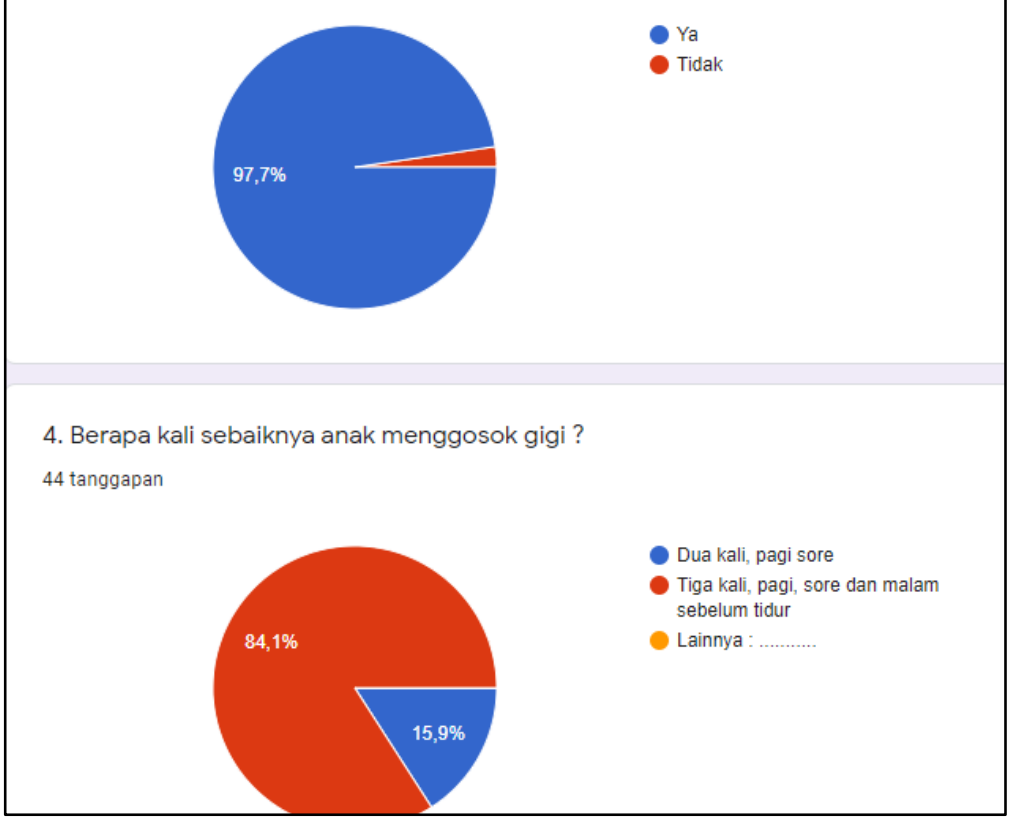

Gambar 5. Pentingnya menggosok gigi dan frekuensi menggosok gigi

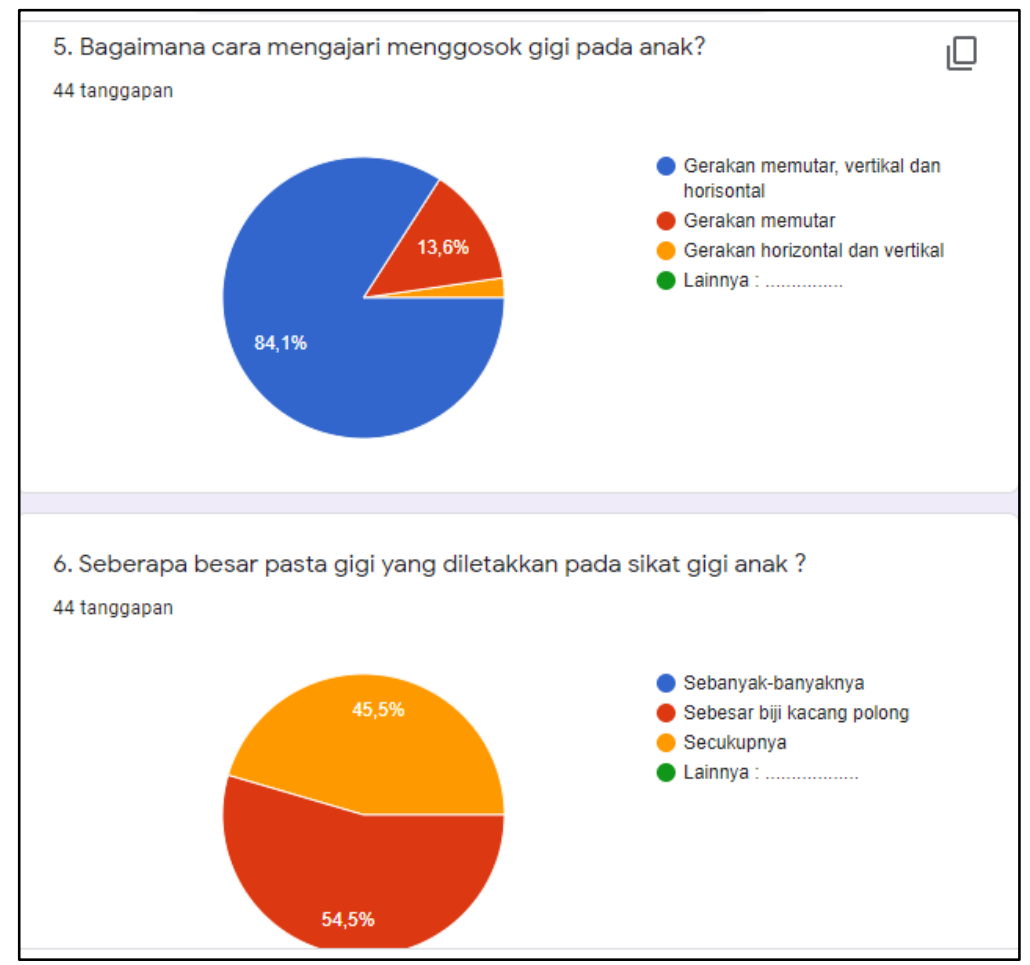

Gambar 6. Cara menggosok gigi dan besaran pasta gigi 
7. Seberapa lama waktu menyikat gigi pada anak?

44 tanggapan

8. Seandainya anak sakit gigi, yang dapat kita lakukan segera adalah :

44 tanggapan

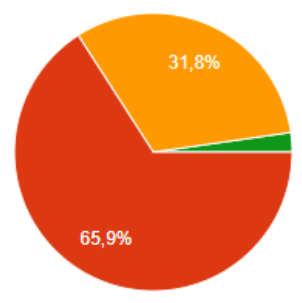

- selama-lamanya

1-2 menit

2-3 menit

Lainnya

- minum obat utk anak

kumur obat kumur atau air

garam hangat

Lainnya

\section{Gambar 7. Waktu menggosok gigi dan jika anak sakit gigi}

9. Seandainya anak bengkak giginya, yang dapat kita lakukan adalah

44 tanggapan

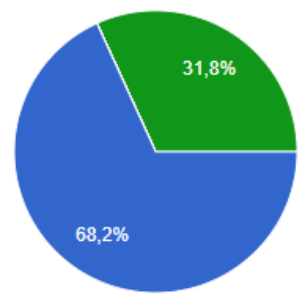

beri obat, kumur garam, segera

ke dokter gigi

beri obat yang manjur

kumur saja

ke dokter gigi segera

- lainnya

\section{Gambar 8. Jika anak bengkak gigi}

10. Seandainya anak terjatuh dan giginya berdarah, pertolongan yang dapat kita lakukan adalah :

43 tanggapan

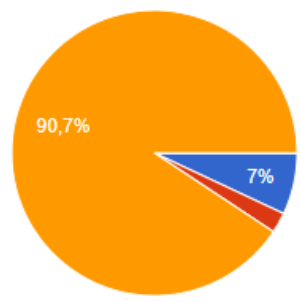

segera bawa ke dokter terdekat

bawa ke IGD atau RS terdekat

kompres es batu, minum obat

anak dan segera ke dokter gigi

Lainnya

Gambar 9. Pertolongan pertama pada anak 
11. Siapa rtanggung jawab jika anak kesakitan gigi saat di sekolah / PAUD :

44 tanggapan

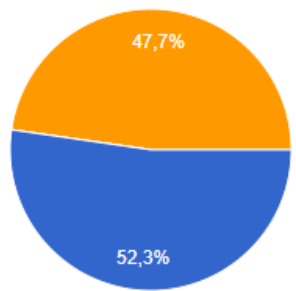

Guru / pengelola

Orang tua

Guru bersama orang tua

- Lainnya

Gambar 10. Penanggung jawab jika anak sakit

12. Seandainya ada pelatihan virtual terkait kesehatan gigi, apakah $\mathrm{Bp} / \mathrm{lbu}$ berkenan mengikuti nya?

41 tanggapan

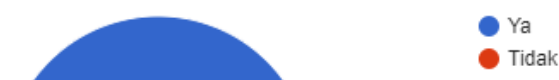

$97,6 \%$

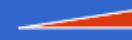

Tidak

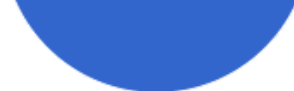

\section{Gambar 11. Pelatihan virual}

13. Apakah pengetahuan terkait kesehatan gigi anak, diperlukan dalam mendukung tugas $\mathrm{Bp} / \mathrm{lbu}$ saat ini?

44 tanggapan

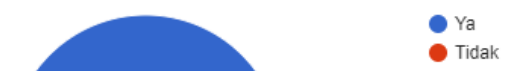

$100 \%$

Gambar 12. Pengetahuan kesehatan gigi anak 


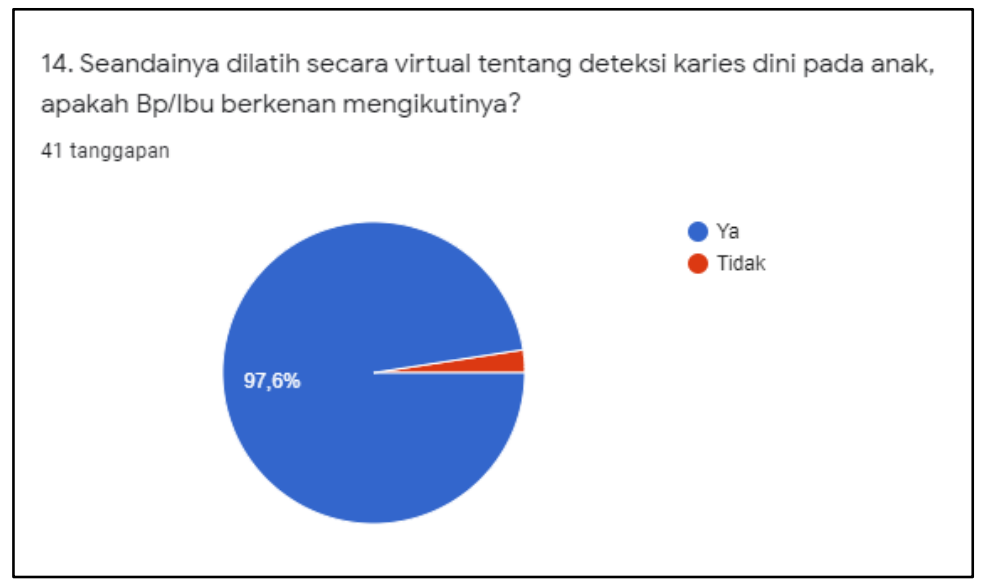

\section{Gambar 13. Pelatihan virtual tentang deteksi karies}

Data kuesioner pada Gambar 4 menunjukkan 100\% guru TK/PAUD setuju bahwa pengetahuan kesehatan gigi merupakan hal yang penting untuk diketahui. Mereka juga menyatakan pada Gambar 5 yakni bahwa menggosok gigi penting untuk anak TK/PAUD dan hanya 2,30 \% yang menyatakan tidak penting. Mereka menyatakan bahwa menggosok gigi sebaiknya dilakukan dua kali sehari $(15,90 \%)$ dan tiga kali sehari $(84,10 \%)$. Pada Gambar 6, hampir semua guru tahu cara menggosok gigi yang baik dan benar $(84,10 \%)$. Adapun besaran jumlah pasta yang diletakkan pada sikat gigi anak adalah sebesar biji kacang polong $(54,50 \%)$ dan 45,50\% menyatakan secukupnya (tanpa ukuran).

Data pada Gambar 7 juga menunjukkan bahwa waktu menyikat gigi anak selama 1-2 menit $(65,9 \%)$ dan 2-3 menit $(31,8 \%)$. Secara umum, mereka mengetahui penanganan segera pada anak yang sakit gigi. Sebanyak 50,00\% responden menyatakan anak perlu minum obat jika sakit gigi, 29,5\% menyatakan cukup kumur air garam hangat atau obat kumur. Pada gambar 8, mereka juga mengetahui jika anak mengalami bengkak giginya, anak segera minum obat, kumur garam, dan segera ke dokter gigi $(68,20 \%)$. Bahkan, 31,80\% menyatakan anak perlu ke dokter gigi segera.

Salah satu manfaat kegiatan ini adalah mengenal masyarakat sekolah secara lebih dekat. Selain itu, kegiatan ini juga mampu menjaring aspirasi yang tumbuh pada masyarakat sekolah, menyerap keluhan-keluhan mereka dan menindaklanjuti lewat kerja sama dengan kapasitas maksimal yang dimiliki institusi ${ }^{9)}$. Pada sisi lain, penggerakan masyarakat sekolah, latihan mediasi, dan sosialisasi adalah penting untuk kalangan institusi pendidikan. Menjamu dan melayani masyarakat sekolah bukanlah hal mudah, tetapi dapat diupayakan. Dosen sebagai salah satu unsur civitas akademica sebaiknya dilibatkan sebagai pembimbing dan motivator. Selain itu, kegiatan ini sebaiknya bekerja sama dengan tenaga medis setempat atau tenaga medis lain profesi agar pelayanan edukasi lebih lengkap dan comprehensive ${ }^{10)}$. Masyarakat sekolah TK/PAUD dan komite sekolah dilibatkan dalam setiap proses pelaksanaan program edukasi. Masyarakat sekolah dapat menyumbang bantuan tenaga, pikiran, pembaharuan, dan kader pembangunan. Pelibatan tokoh masyarakat sekolah juga sekaligusmerupakan bentuk sikap menghargai peran mereka ${ }^{11)}$. Pelibatan peran serta masyarakat sekolah melalui komite sekolah dan peran orang tua/wali, terutama ibu, adalah hal yang penting karena ibu merupakan soko guru pada masyarakat. Kerja sama lintas sektoral (perangkat sekolah,puskesmas setempat, tim medis, penyelenggara, pemerintah setempat) adalah hal tidak boleh dilupakan ${ }^{11)}$. Penggerakan 
masyarakat sekolah lewat wanita dapat dilakukan melalui berbagai komunitas dan tokoh wanita di kalangan tertentu. Pelibatan peran ibu bertujuan agar ibu memotivasi keluarga masing-masing untuk berpartisipasi dalam kegiatan tersebut ${ }^{10)}$. Gambar 11 menunjukkan bahwa jika ada pelatihan virtual, orang tua menyetujui untuk mengikuti kegiatannya. Selain itu, pada Gambar 13 diketahui bahwa orang tua juga setuju jika ada pelatihan deteksi dini.

\section{Simpulan}

Pengetahuan tentang menyikat gigi, cara, besarnya pasta gigi yang diperlukan untuk menyikat gigi, serta pertolongan kedaruratan saat anak sakit gigi dan bengkak giginya perlu ditingkatkan di kalangan pendidik guru TK dan PAUD. Hal ini terbukti belum $100 \%$ jawaban benar dari data kuesioner.

Kesadaran pentingnya kepedulian sekolah dalam masalah kesehatan gigi dan mulut dibuktikan dengan $97,60 \%$ - 100\% responden setuju terkait adanya pelatihan virtual dan penambahan pengetahuan tentang kesehatan gigi anak.

\section{Ucapan Terima Kasih}

Kami mengucapan terima kasih kepada LP3 UMY yang telah memberi dana hibah pengabdian masyarakat melalui Program Kemitraan Masyarakat (PKM) tahun usulan 2019 dan tahun pelaksanaan 2020.

\section{DAFTAR PUSTAKA}

Anonim, 2015, Kondisi Kesehatan Gigi di Dunia, WHO.

Kidd, Edwina A.M and Bechal, S.J. (1992). Dasar-Dasar Karies dan Penanggulangannya.Jakarta:EGC

Tarigan, Rasinta. (2013). Karies Gigi (2 ${ }^{\text {nd }}$.ed.). Jakarta:EGC

Anonim, 2009, Profil Kesehatan, Depkes RI

Anggraini, 2011, Karies pada Anak Sekolah Sapen, Makalah pada Seminar Kedokteran Gigi UMY, Yogyakarta

Angela, A. (2005). Pencegahan Primer pada Anak yang Beresiko Karies Tinggi, Jurnal.

Susilawati, S. Samiaty, A. dan Muhibat, S. (2007). Penilaian Status Risiko Karies Gigi pada Murid Kelas I dan V di SDN Cinunuk Bandung. Jurnal Kedokteran Gigi Universitas Padjajaran.

Anonim, 1993, Dinkes DKI, Jakarta

Kartika Sari, 2009, Kondisi Kesehatan Gigi di Indonesia, Jakarta

Anggraini, 2010, Penggerakan pada Masyarakat, Kedokteran Gigi UMY, Yogyakarta Anonim, 1997, Kuliah Kerja Nyata, UGM, Yogyakarta. 